Running Head: Multiple Categorization and Health Disparities

\title{
Encouraging Majority Support for Immigrant Access to Health Services: Multiple Categorization and Social Identity Complexity as Antecedents of Health Equality
}

\author{
Francesca Prati ${ }^{1}$, Richard J. Crisp ${ }^{2}$, Felicia Pratto $^{3} \&$ Monica Rubini $^{1}$ \\ ${ }^{1}$ Department of Psychology, Alma Mater Studiorum University of Bologna, Italy \\ ${ }^{2}$ Aston Business School, Aston University, UK \\ ${ }^{3}$ Department of Psychology, University of Connecticut, USA
}

\begin{abstract}
Author note
Correspondence regarding this article should be sent to Francesca Prati at the University of Bologna, Department of Psychology, 5 Berti Pichat, 40126, Italy; phone number: 0039051 2091826; email: francesca.prati@unibo.it
\end{abstract}

\section{Abstract}


Health disparities between groups remain even after accounting for established causes such as structural and economic factors. The present research tested, for the first time, whether multiple social categorization processes can explain enhanced support for immigrant health (measured by respondents' behavioral intention to support immigrants' vaccination from A H1N1disease by cutting regional public funds). Moreover, the mediating role of individualization and the moderating role of social identity complexity were tested. Findings showed that multiple versus single categorization of immigrants lead to support their right to health and confirmed the moderated mediation hypothesis. The potential in developing this sort of social cognitive intervention to address health disparities is discussed.

Key words: Health Disparities, Multiple Categorization, Social Identity Complexity Word Count: 108

Manuscript Word Count: 7023

The global rise in migration, over recent decades, has increased the multicultural diversity of modern European societies. The Secretary-General of the United Nations (UN), Ban Ki-Moon made 
an impassioned call for Europe to seize the opportunities presented by immigration and to resist those who demonized these newcomers as 'the other'. In particular, he addressed the fact that "migrants are being denied basic human rights" (United Nations, 2010). Despite the political commitment of United Nations in promoting immigrants' social integration, limitations or denials of basic rights are still daily occurrences for migrants in Europe, and the debate on this issue has a new urgency because of the recent rise in migrants being smuggled by sea to southern Europe, especially Italy (from 1998 till 2014, an average of almost 40,000 persons a year). Italian student respondents were used in the present research because Italy recently has faced a growing number of arrivals by sea (Nascimbene \& Di Pascale, 2011), making it necessary to find places and resources to fulfill immigrants/refugees' basic needs (i.e., lodging, feeding, medical assistance).

Amongst basic human rights, the right to health is one of the most discussed and debated. Indeed, health disparities can be seen as one of the most heinous forms of intergroup discrimination because they can endanger people' lives. Immigrants have poorer health on average than native group members and this implies higher levels of health problems and a significantly shorter life expectancy (Matthews \& Gallo, 2011; Penner, Albrecht, Orom, Coleman, \& Underwood, 2010). The persistence and pervasiveness of health disparities relies on a social psychological process: intergroup differentiation. A great deal of evidence has shown that categorization into 'us' and 'them' lies at the heart of intergroup discrimination (Tajfel, Billig, Bundy, \& Flament, 1971; Tajfel $\&$ Turner, 1979; for a review see Tajfel, 1978). In turn, this differentiation justifies discriminative treatments towards outgroup (non-native) members in the form of exclusionary access to health resources.

On the other hand, research has shown that increasing the number and/or complexity of social categories simultaneously attributed to outgroup members reduces intergroup differentiation and can work as a buffer against discrimination (Crisp, Hewstone, \& Cairns, 2001; Crisp, Hewstone, \& Rubin, 2001; Deschamps \& Doise, 1978; Hall \& Crisp, 2005). Similarly, the higher the social identity complexity characterizing a person, the more he/she favours intergroup tolerance 
and social inclusion (Roccas \& Brewer, 2002). The goal of the present research was to investigate whether multiple categorization of immigrants could increase behavioral intention meant to overcome health disparities toward disadvantaged outgroup members. Moreover, the mediating role of individualization (that is, the perception of outgroup members as single individuals as a consequence of their multiple categorization) and the moderating role of respondents' social identity complexity (Roccas \& Brewer, 2002) was tested.

\section{Health Disparities}

The right to health should imply equal and timely access to health care services, the provision of health-related education and information and equity in the access to health care services for equal health needs (World Health Organisation, Fact Sheet $\mathrm{n}^{\circ} 31$ "The Right to Health"). Health disparities refer to differences in health care services across groups and it is a pervasive, persistent and prevalent phenomenon across cultures (see Penner et al., 2010; Smedley, Stith, \& Nelson, 2003 for reviews). Several explanations for intergroup health disparities have been proposed: genetic populations' susceptibility to different diseases (Pettaway, 1999), socioeconomic differences (IOM, 2003; Sentell \& Halpin, 2006). Beyond these factors, the psychological factors of prejudice and stereotyping may exert an independent influence or, even better, explain the impact of the above cited social structural factors on health care (Major, Mendes, \& Dovidio, 2013; Williams \& Jackson, 2005). Indeed, health disparities remain even after accounting for traditional explanations such as structural and economic factors (Penner, et al., 2010; Smedley et al., 2003). In this regard, Schniittker and McLeod (2005) suggested that without a consideration of social psychology theories, health disparities researchers may inadequately capture the relevance of intergroup discrimination and narrow social identity as underlying factors of the promotion of intergroup health equity. For instance, Black women are less likely than White women to receive testing for osteoporosis (Mudano et al., 2003) and, when women of both races have been diagnosed with osteoporosis, Black women are less likely to receive the appropriate medication than are White 
women in the U.S. (Mikuls, Saag, George, Mudano, \& Banerjee, 2005). Taken together, these findings implicate the role of racial discrimination in health care.

Along this line of reasoning, strategies to reduce the impact of intergroup discrimination can also help to reduce social disparities in health by improving the quality of care for "vulnerable" groups. Studies have shown that when treatment disparities are eliminated, disparities in health outcomes are substantially attenuated or absent (Bach et al., 2002). Indeed, evidence continues to mount suggesting that perceived discrimination is a psychosocial stressor and thus it is one of the main risk factor for multiple health outcomes (Williams \& Mohammed, 2009). This implies that strategies that reduce intergroup discrimination may attenuate also harmful outcomes of health disparities elicited by discrimination.

\section{Multiple Categorization}

Research on the reduction of intergroup discrimination can be distinguished between strategies that focus on the impact on attitudes towards others and strategies that focus on the impact on one's sense of self. Research on strategies that focus on others has shown that multiple categorization reduces intergroup discrimination (Crisp, Hewstone \& Rubin, 2001). Specifically, while people are cognitively predisposed to rely on simple, dichotomous ingroup-outgroup categorizations (Crisp \& Meleady, 2012), research has shown multiple categorization techniques to reduce traditional forms of intergroup bias. So when participants are instructed to think about multiple affiliations compared to a single affiliation characterizing an outgroup target, intergroup stereotypes and prejudice (Crisp, Hewstone, \& Cairns, 2001; Crisp, Hewstone, \& Rubin, 2001) and dehumanization (Albarello \& Rubini, 2012; Albarello \& Rubini, 2015; Prati, Vasiljevic, Crisp, \& Rubini, 2015) are reduced. Similarly, when people are asked to generate as many alternative spontaneous affiliations of outgroup members as possible, intergroup prejudice is attenuated (Hall \& Crisp, 2005). The same occurs using implicit evaluations (Crisp, Stone, \& Hall, 2006) and measures of stereotype threat (Rosenthal \& Crisp, 2006; Rosenthal, Crisp, \& Suen, 2007). Multiple 
categorization has even been shown to attenuate linguistic discrimination of outgroup members (Prati, Menegatti, \& Rubini, 2015; Rubini, Moscatelli, \& Palmonari, 2007). When immigrants were presented as having multiple affiliations, negative terms used to describe them were even more concrete that positive terms suggesting that linguistic discrimination conveyed by language abstraction disappeared. Multiple compared to simple categorization of Black people can hinder dehumanization (Albarello \& Rubini, 2012), the pervasive tendency to consider outgroup members as less human than ingroup members (Haslam, 2006; Leyens et al., 2000; 2001). The particular type of multiple categorization that is counter-stereotypic category combination (i.e., female - mechanic, male - midwife) increases humanization and tolerance towards multiple stigmatized outgroups (Prati, Vasiljevic et al., 2015; Vasiljevic, \& Crisp, 2014).

The positive impact of multiple categorization can be explained by a cognitive re-construal of the target as an individual rather than a (oppositional) group member (Crisp, Hewstone, \& Rubin, 2001). Crisp and Hewstone's (2007) differentiation-decategorization model contends that when two convergent ingroup or outgroup categories are combined there is an increase in intergroup differentiation which, in turn, augments intergroup bias. Contrarily, when there are a large number of categories and/or those categories are cross-cutting, a decategorization process takes place leading to a systematic reassessment and inhibition of existing stereotypic representations. Decategorization therefore refers to the process of switching from categorization and the reliance on social stereotypes to individualization and the use of accurate information on others.

\section{Social Identity Complexity}

Research focusing on socio-cognitive processes involved in impression formation of the self has shown that perceived social identity complexity promotes intergroup tolerance (Roccas \& Brewer, 2002). People self-define as members of many groups and may not consider their identity to be rooted in only one group (e.g., Pickett \& Brewer, 2001). Social identity complexity defines one's more or less complex cognitive representation of the interrelationships among his/her multiple 
ingroup identities. It refers to the degree of overlap perceived to exist between groups of which an individual is simultaneously a member (ingroups). Roccas and Brewer (2002) proposed that individuals' representations of their multiple group memberships can vary along the dimension of complexity and they operationalized two distinct measures of it. When one's representation is low in complexity, it is an indication that one perceives a high overlap between the actual members of his/her various group memberships (overlap measure) as well as high similarity between the typical characteristics of his/her various group memberships (similarity measure). In contrast, when one's representation is high in complexity, it is an indication that one perceives a high distinction (low overlap) between the actual members of his/her various group memberships as well as low similarity between the typical characteristics of his/her various group memberships. A complex identity structure is more inclusive than a simple or intersection one because it is the sum and not the crossing of multiple ingroups (overlap measure) and characteristics (similarity measure).

Studies have shown that those with highly complex identity structure give lower importance to conservatism and power values, have higher tolerance for diversity, and have low explicit and implicit racial attitudes above and beyond any effects of ideology and cognitive style (Brewer \& Pierce, 2005; Miller, Brewer, \& Arbuckle, 2009). Intergroup contact is positively, and distinctiveness threat negatively, associated with a highly complex identity structure which in turn explains the effects of contact and distinctiveness threat on intergroup attitudes (Schmidt, Hewstone, Tausch, Cairns, \& Hughes, 2009). Considering minority group members, those with highly complex identity structure tend to identify more with the national group and distance themselves less from the host society showing lower ingroup bias than those with a less complex identity structure (Verkuyten \& Martinovic, 2012). Moreover, social identity complexity was also shown to be a sequential mediator of the effects of social dominance orientation (SDO; Pratto, Sidanius, Stallworth, \& Malle, 1994; Pratto et al., 2013) on humanization and support for Arabs' autonomy (Prati, Moscatelli, Pratto, \& Rubini, 2015). 


\section{The Present Research}

In the present research, we tested whether multiple categorization can reduce disparities in health resource allocation. Knowing that health disparities are related to intergroup discrimination (Bach et al., 2002; Major et al., 2013), and intergroup discrimination is triggered by social categorization (Tajfel et al., 1971), we expected that increasing the number of categories simultaneously attributed to outgroup members would improve the behavioral intention to financial support outgroup members' health ${ }^{1}$. Moreover, we investigated social processes that may be involved in multiple categorization effects on health disparities. In particular, we expected that individualization of outgroup members would mediate multiple categorization effects. Furthermore, we expected that social identity complexity would moderate the effect of multiple categorization. Specifically, we hypothesized that individuals with low complexity in social identity would increase the financial support for outgroup members' health when they were induced to consider themselves in terms of multiple categories. Conversely, individuals with high complexity in social identity would equally support outgroup members' health-care expenditures independently of their categorization condition.

According to Ajzen and Fishbein (2000; see also Ajzen, 1991; Fishbein \& Ajzen, 1975), the best predictor of a behavior is behavioral intention, thus we measured majority members' behavioral intention to support immigrants' right to health-care, specifically, by supporting vaccination for immigrants. To measure behavioral intentions to prevent immigrants from contracting the disease at stake, thus saving their lives, we adapted a decision making task from Pratto and Glasford (2008). These authors asked respondents to choose between alternative options varying the number of ingroup and outgroup lives to save (or lose) versus some material consequence for the other group. Evidence showed that in intergroup competitive contexts people attribute a lower value to outgroup members' human lives compared to those of their compatriots, choosing the option to save the life of a lower number of ingroup members compared to a higher 
number of outgroup members. This effect implies that social categorization influences the discrepant attribution of value to human life of ingroup relative to outgroup members.

\section{Method}

Pilot study. Students from an Italian University $(\mathrm{N}=170)$ took part in two preliminary studies to select equally meaningful affiliations of participants. In the first study, 20 participants $\left(M_{\text {age }}=20.59, S D=0.74 ; 55 \%\right.$ women $)$ were asked to list as many important social groups to which they belong as they could. In a second study, a new sample of one hundred and fifty participants $\left(M_{\text {age }}=20.87, S D=3.95 ; 51 \%\right.$ women $)$ rated to what extent they identify with the 6 most cited affiliations, which were nationality, age, gender, occupation, parenthood and region on a 7-points scale $(1=$ not at all, $7=$ very mисh $)$. Paired sample $t$-tests showed no significant differences in participants' identification in the six affiliations $\left(M_{\text {nationality }}=5.08 ; S D=1.70 ; M_{\text {age }}=5.08 ; S D=\right.$ $1.70 ; M_{\mathrm{gender}}=5.22, S D=1.74 ; M_{\text {occupation }}=4.93, S D=1.78 ; M_{\text {parenthood }}=5.03 ; S D=1.65 ;$ $\left.M_{\text {regionregion }}=4.88 ; S D=1.81\right)$, all $p \mathrm{~s}>.17$.

Participants and design. One hundred and twenty one undergraduate students $\left(M_{\text {age }}=\right.$ $23.12, S D=1.51 ; 69 \%$ women) from an Italian University participated in this study on a voluntary basis. They were randomly assigned to one of the 4 conditions: simple, multiple ingroup, multiple outgroup, multiple mixed categorization.

Procedure and materials. Participants provided some basic information to ensure that only those who were ingroup members on the social categories considered were included. After that in the simple categorization they were asked to describe their impressions of an immigrant. In the multiple ingroup categorization, the immigrant group target was depicted as composed of youngs, students, living in the same town, having no children and being of the same gender with the participants (five ingroups of the participants). In the multiple outgroup categorization, the immigrant group target was depicted with five affiliations different from those of participants that is , adults, workers, living in countryside, having children and of the opposite gender with the 
participants (five outgroups of the participants). In the multiple mixed categorization the immigrant group target was depicted in terms of three categorizations shared between participants and the target and three unshared categorizations. They then completed the dependent measures.

Social identity complexity was assessed by using the overlap measure (Brewer, Gonsalkorale, \& van Dommelen, 2013). Participants were asked to rate the perceived overlap between all pairs of three groups considered (professional/ political/ national). Namely, they were asked to answer the same question repeated for all possible pair combinations. All pairs were rated in both directions (e.g., "When you think about people who are Italians, how many belong to your political group?" and "When you think about people who belong to your political group, how many are Italians?"). Thus, each participant provided six ratings. The response scale ranged from 0 to 100 $(0=$ none are, $5=$ half are, $100=$ all are $)$. Scores were then reversed so that higher scores denote higher overlap complexity, and were averaged to obtain a measure of $\operatorname{SIC}(\alpha=.85){ }^{2}$

\section{Dependent Measures.}

Individualization. Drawing from Hutter, Wood and Turner (2013), participants were asked to indicate " To what extent do you consider the target group described above as ..." $(1=$ individuals, 7 = group members); "To what extent do you consider the target group described above as unique individuals" $(1=$ not at all, $7=$ very $m u c h)$; "To what extent do you think that the target qualifies as typical group member" $(1=$ not at all, $7=$ very much $)$; "How similar are individual members of the above group to other members of the same group?" $(1=$ not at all similar, $7=$ very similar . Items 1, 3, 4 were reversed-coded, such that higher scores on each items represented higher individualization. An index of individualization $(\alpha=.69)$ was created by collapsing items into a single composite score.

Financial support for immigrants' vaccination. Drawing on Pratto and Glasford's study (2008), we designed a decision making task to test respondents' behavioral intention to financially support immigrants' vaccination. Participants read a short paragraph informing them that immigrants had a higher risk of contagion from the virus A H1N1, very active in Europe at the time 
of the study. They had then to decide to what extent they judged it feasible to cut regional funds for public education to instead fund vaccination of immigrants who were presented as a social category with a high risk of getting affected by the virus A H1N1. Participants chose among seven options presented in a random order and varying systematically the percentage of regional educational funds cut and the number of immigrants that could benefit from the vaccine.

Each option pitted a policy concerning some number of immigrants' lives that could be saved $(2000,5000,8000,11000,14000,17000,20000)$ against a policy with the correspondent cut of regional funds $(0,2 \% ; 0,5 \% ; 0,8 \% ; 1,1 \% ; 1,4 \% ; 1,7 \% ; 2 \%)$. Participants were asked to choose the option they would prefer among seven ones from 1 ( $0.2 \%$ public funds cutting/2000 immigrants can benefit from the A H1N1 vaccine) to 7 (2\% public funds cutting/200000 immigrants can benefit from the A H1N1 vaccine).

\section{Results}

Individualization. A one-way ANOVA on the measure of individualization showed a main effect of categorization, $F(3,117)=2.60, p=.04, \eta^{2}=.07$. In the multiple ingroup $(M=4.33, S D=1.42)$, multiple outgroup $(M=4.20, S D=0.99)$, and multiple mixed categorizations $(M=4.26, S D=1.31)$, individualization ratings were higher than for simple categorization $(M=3.41, S D=1.96)$, all $p$ s < .04. Multiple ingroup, multiple outgroup and multiple mixed categorizations did not differ from each other, all $p s>.072$. Thus, it is multiple categorization versus simple categorization that matters most.

Financial support for immigrants' vaccination. A one-way ANOVA on the measure of financial support for immigrants' vaccination showed a main effect of categorization, $F(3,117)=2.82, p=$ $.04, \eta^{2}=.07$. In the multiple ingroup $(M=5.17, S D=1.87)$, multiple outgroup $(M=4.90, S D=$ 1.75), and multiple mixed categorizations $(M=5.23, S D=1.59)$, ratings of financial support for immigrants' vaccination were higher than for simple categorization $(M=3.87, S D=1.54)$, all $p$ s < 
.04. Multiple ingroup, multiple outgroup and multiple mixed categorizations did not differ from each other, all $p s>.54$.

Mediation analysis. Means, standard deviations and intercorrelations are presented in Table 1 showing no multicollinearity between variables. Thus we tested the mediation of individualization and the moderation of social identity complexity on multiple categorization effects on support for vaccination. Because there were no significant differences between multiple ingroup, outgroup and mixed categorization conditions for dependent variables, these conditions were collapsed to form a dichotomous variable: single vs. multiple categorization. We employed the Hayes and Preacher and Myers's (2011) PROCESS macro to test a model using categorization as the independent variable, support for vaccination as the dependent variable, individualization as the mediator, and SIC as the moderator. This macro uses an ordinary least squares logistic regression-based path analytical framework to analyze statistical models involving moderation, mediation, and their combination, termed conditional process modeling. The moderated mediation of individualization in the relationship between categorization type and financial support for immigrants' vaccination was tested at two values of SIC (computed at the mean \pm 1 SD levels), with higher scores representing higher SIC. First, we examined the moderating role of SIC on multiple categorization effect on support for vaccination. Categorization significantly predicted support for vaccination $(B=1.05, S E$ $=0.37, p=.005)$. Specifically, multiple categorization of immigrants was associated with higher level of support for vaccination and single categorization of immigrants was associated with lower level of support for vaccination. SIC did not predict support for vaccination $(B=0.03, S E=0.01, p$ $=.08)$, but there was an interaction between SIC and categorization $(B=-0.04, S E=0.01, p=.03)$. As shown in Figure 1, tests of simple slopes across levels of SIC revealed a significant and strong association between immigrants' categorization and support for vaccination for participants with low $\operatorname{SIC}(B=0.60, S E=0.19 ; \mathrm{CI}=\mathrm{LL}: .21$, UL 0.99) and a non-significant relationship for those with high SIC $(B=-0.00, S E=0.18 ; \mathrm{CI}=\mathrm{LL}:-.37$, UL 0.36). 
The mediating role of individualization in the relationship between categorization and support for vaccination was tested at the two values of low and high SIC. Boot-strap-based confidence intervals (95\%) for the indirect effect were generated by taking 5,000 samples from the original data-set. For participants who scored low in SIC, categorization predicted support for vaccination $(B=0.43, S E$ $=0.18 ; p=.01)$ and individualization $(B=0.24, S E=0.12 ; p=.04)$. Individualization predicted support for vaccination $(B=0.35, S E=0.10 ; p=.006)$. When both categorization and individualization were included in the regression equation, categorization did not predict support for vaccination $(B=0.21, S E=0.18 ; p=.09)$ but individualization did predict it $(B=-0.32, S E=0.12$; $p=.02$ ). For participants who scored high in SIC, categorization did not predict support for vaccination $(B=-0.06, S E=0.16 ; p=.68)$ neither individualization $(B=0.07, S E=0.18 ; p=.05)$. Individualization predicted support for vaccination $(B=0.21, S E=0.18 ; p=.04)$. When both categorization and individualization were included in the regression equation, categorization did not predict support for vaccination $(B=-0.07, S E=0.16 ; p=.66)$ and individualization did not predict it $(B=0.15, S E=0.15 ; p=.31)$. The cut-off value in the lower tail of the bootstrap distribution of conditional indirect effects was above zero for those above the mean for SIC, indicating that the conditional indirect effect of multiple categorization on support for vaccination is significantly different from zero (at $p<.05$ ). Thus, as predicted, SIC moderated the indirect effect of multiple categorization on support for vaccination through individualization $(B=0.003, S E=0.002 ; \mathrm{CI}=$ LL: $-.01, \mathrm{UL}-.0002){ }^{3}$

\section{General Discussion}

The present research showed for the first time that multiple categorization of immigrants can increase the behavioral intention to financially support immigrants' health. Moreover, the effect of immigrants' multiple categorization on intentional support for their vaccination was mediated by their individualization and moderated by respondents' social identity complexity. Thus, this study has demonstrated the interplay between multiple categorization and social identity complexity as 
effective strategies to promote the right to health of a discriminated target group such as immigrants. It is especially important that our experimental manipulations of categorization influenced most the participants who are generally low in social identity complexity. People with this tendency are also those most prejudiced against outgroups, among whom finding ways to increase their greater tolerance of and integration with outgroups is most relevant. For those already high in social identity complexity, their habitual way of thinking about others as individuals with value was not even changed by having them do very simple categorizations of outgroups.

These findings extend previous evidence on the beneficial role of multiple categorization (Crisp \& Hewstone, 2007) in reducing linguistic outgroup discrimination (Prati, Menegatti et al., 2015) and dehumanization (Prati, Vasiljevic et al., 2015) by showing its impact in promoting behavioral intentions towards outgroup members. In this vein, multiple categorization can be considered as a socio-cognitive antecedent to overcome health disparities among social groups.

It is also worth to noting that the behavioral intention to financially support immigrants' vaccination may imply that respondents value outgroup members' lives as much as they do with their own group's lives, thus acknowledging their equal humanity. This finding adds to the literature on the beneficial role of this intervention in reducing outgroup discrimination (e.g., in the form of dehumanization; Prati, Vasiljevic et al., 2015).

Furthermore, we found effects for how much participants viewed immigrants as individuals than as groups as a main effect and mediator. These results showed that individualization of immigrants explained the beneficial role of multiple categorization on behavioral intention to financially support immigrants' vaccination. This is in line with Crisp et al.'s (2001) contention that beneficial effects of multiple categorization are due to perceivers coming to no longer rely on categorical bases for social judgment. Indeed, multiple categorization reduces the salience of each social category in favor of an individuated and original evaluation of the target which can dramatically improve intergroup relationships. 
Results highlight the beneficial effect of multiple categorization strategy per se independently of the type of categories considered (whether these are shared or unshared between perceivers and the target) ruling out the role of ingroup shared affiliaions and perceived similarity with the target.

One could also wonder whether the same individuation effect leading to enhanced financial support for immigrants'health would be obtained also when considering multiple negative categorization. Given that negatively valence attributes, characteristics or categories are more diagnostic and threatening than positive ones, we would not expect multiple negative categorizations to produce the effect of supporting outgroup members' health. In such a case the explanation would be motivational rather than calling into play cognitive complexity. More specifically, considering multiple negative categorizations of outgroup members would lead to individualization of immigrants (decategorization effect) as it happens when multiple positive categorizations are at stake. However, reiterating multiple negative means of immigrants' definition would augment perceived threat from them because the additive effect of negatively valence categories would persist in a final negative individuated impression. In this case, the "beneficial" cognitive effect of decategorization would be overridden by the motivational effect of perceived threat.

In a novel way, we also found evidence for the "compensatory" role of social identity complexity in promoting positive behavioural intentions towards outgroup members when perceivers are exposed to single categorizations. Indeed individuals with lower social identity complexity individuated more following multiple categorization, and increased willingness to provide financial support for their health. Conversely, individuals with highly complex social identity showed equal support for immigrants' health in multiple versus simple categorizations of them. In this vein, multiple categorization appears an effective strategy to attenuate intergroup health disparities especially for individuals with less complex social identity. 
Taken together, these findings show the "complementarity" of multiple categorization and social identity complexity approaches for promoting a climate in which health policies favoring equity among social groups. Thinking about others and oneself in complex terms can build coalition allies as a precondition of social change and social inclusion.

Haslam, Jetten, Postmes and Haslam (2009) emphasized that groups are important for their members because they enhance self-esteem and sense of worth. These effects can buffer well-being when these are threatened or discriminated. Accordingly, far from being "just another" factor that impinges upon the health of individuals, social identities - and the notions of "us-ness" that they both embody and help create — are central to health and well-being. Our findings support and extend this assumption by showing that increasing the number of social identities simultaneously attributed to others or themselves, can enlarge the boundaries of social groups and, as we have showed in terms of behavioral intentions, contribute to the well-being of much larger groups of people.

Of course this research has some limitations. If on the one side, the results are promising because we showed the strength of multiple categorization and social identity complexity in leading to the intention of supporting intergroup health equality, on the other side we acknowledge that the results were obtained with a relatively small sample of Italian students. Moreover, we focused on an accessible and relevant group target such as immigrants (cf. Bargh \& Thein, 1985; Higgins \& King, 1981), but at the moment, we cannot generalize the effectiveness of these interventions to other targets. Future research should extend the validity of these interventions to other targets and other groups sample. Further research is needed to test the robustness of this evidence. It would be also relevant to test additional kinds of human rights in order to generalize the strength of the present results.

\section{Conclusions}

Overall, the present research highlighted that multiple categorization and social identity approaches can enrich the understanding of the relationship between social psychological processes and health disparities. It suggests that just as health disparities should be addressed in economic and 
political terms, they should also be addressed in psychological terms. It is our hope that the present research will contribute to the implementation of interventions and policies that effectively aim to reduce health disparities between different social groups in contemporary societies. 


\section{References}

Ajzen, I. (1991). The theory of planned behavior. Organizational Behavior and Human Decision Processes, 50, 179-211. Doi:10.1016/0749-5978(91)90020-T

Ajzen, I., \& Fishbein, M. (1977). Attitude-behavior relations: A theoretical analysis and review of empirical research. Psychological Bulletin, 84, 888-918. Doi:10.1037/0033-2909.84.5.888

Ajzen, I., \& Fishbein, M. (2000). Attitudes and the attitude-behavior relation: Reasoned and automatic processes. European Review of Social Psychology, 11, 1-33.

Doi:10.1080/14792779943000116

Albarello, F., \& Rubini, M. (2012). Reducing dehumanisation outcomes towards Blacks: The role of multiple categorisation and of human identity. European Journal of Social Psychology, 42, 875-882. Doi:10.1002/ejsp.1902

Albarello, F., \& Rubini, M. (2015). The role of reduced humanity in producing linguistic discrimination. Personality and Social Psychology Bulletin, 41, 224-236. Doi: $10.1177 / 0146167214561195$

Bach, P. B., Schrag, D., Brawley, O. W., Galaznik, A., Yakren, S., \& Begg, C. B. (2002). Survival of blacks and whites after a cancer diagnosis. Jama, 287, 2106-2113. Doi:10.1001/jama.287.16.2106

Bargh, J. A., \& Thein, R. D. (1985). Individual construct accessibility, person memory, and the recall-judgment link: The case of information overload. Journal of Personality and Social Psychology, 49, 1129-1146. Doi:10.1037/0022-3514.49.5.1129

Brewer, M. B., Gonsalkorale, K., \& van Dommelen, A. (2013). Social identity complexity: Comparing majority and minority ethnic group members in a multicultural society. Group Processes \& Intergroup Relations, 16, 529-544. Doi:10.1177/1368430212468622

Brewer, M. B., \& Pierce, K. P. (2005). Social identity complexity and outgroup tolerance. Personality and Social Psychology Bulletin, 31, 428-437. Doi:10.1177/0146167204271710 
Crisp, R. J., \& Hewstone, M. (2008). Multiple social categorization. Advances in Experimental Social Psychology, 39, 163-254. Doi:10.1016/S0065-2601(06)39004-1

Derose, K. P., Escarce, J. J., \& Lurie, N. (2007). Immigrants and health care: Sources of vulnerability. Health Affairs, 26, 1258-1268.

Hewstone, M., Rubin, M., \& Willis, H. (2002). Intergroup bias. Annual Review of Psychology, 53, 575-604. Doi:10.1146/annurev.psych.53.100901.135109

Crisp, R. J., Hewstone, M., \& Cairns, E. (2001). Multiple identities in Northern Ireland: Hierarchical ordering in the representation of group membership. British Journal of Social Psychology, 40, 501-514. Doi:10.1348/014466601164948

Crisp, R. J., Hewstone, M., \& Rubin, M. (2001). Does multiple categorization reduce intergroup bias? Personality and Social Psychology Bulletin, 27, 76-89.

Doi:10.1177/0146167201271007

Crisp, R. J., \& Meleady, R. (2012). Adapting to a multicultural future. Science, 336, 853-855. Doi:10.1126/science.1219009

Deschamps, J. C., \& Doise, W. (1978). Crossed category memberships in intergroup relations. In H. Tajfel (Ed.), Differentiation Between Social Groups: Studies in the Social Psychology of Intergroup Relations (pp. 141-158). London, UK: Academic Press.

Dovidio, J. F., Mann, J., \& Gaertner, S. L. (1989). Resistance to affirmative action: The implications of aversive racism. In Affirmative Action in Perspective (pp. 83-102). New York, NY, USA: Springer. Doi:10.1007/978-1-4613-9639-0_7

Duckitt, J. (2006). Differential effects of right wing authoritarianism and social dominance orientation on outgroup attitudes and their mediation by threat from and competitiveness to outgroups. Personality and Social Psychology Bulletin, 32, 684-696.

Doi:10.1177/0146167205284282 
Esses, V. M., Dovidio, J. F., Jackson, L. M., \& Armstrong, T. L. (2001). The immigration dilemma: The role of perceived group competition, ethnic prejudice, and national identity. Journal of Social Issues, 57, 389-412. Doi:10.1111/0022-4537.00220

Esses, V. M., Hodson, G., \& Dovidio, J. (2003). Public attitudes toward immigrants and immigration: Determinants and policy implications. In C. M. Beach, A. G. Green, \& J. G. Reitz (Eds.), Canadian Immigration Policy for the 21st Century (pp. 507-535). Montreal, Canada: McGill- Queen's Press.

Esses, V. M., Jackson, L., \& Armstrong, T. (1998). Intergroup competition and attitudes toward immigrants and immigration: An instrumental model of group conflict. Journal of Social Issues, 54, 699-724. Doi:10.1111/j.1540-4560.1998.tb01244.x

Fishbein, M., \& Ajzen, I. (1975). Belief, Attitude, Intention and Behavior: An Introduction to Theory and Research. Reading, MA: Addison-Wesley Publishing Co.

Fiske, S. T., \& Neuberg, S. L. (1990). A continuum model of impression formation, from category-based to individuating processes: Influence of information and motivation on attention and interpretation. In M. P. Zanna (Ed.), Advances in Experimental Social Psychology (Vol. 23, pp. 1-74). New York, NY, USA: Academic Press.

Hall, N., \& Crisp, R. J. (2005). Considering multiple criteria for social categorization can reduce intergroup bias. Personality and Social Psychology Bulletin, 31, 1435-1444. Doi:10.1177/0146167205276084

Haslam, N. (2006). Dehumanization: An integrative review. Personality and Social Psychology Review, 10, 252-264. Doi:10.1207/s15327957pspr1003_4

Haslam, S. A., Jetten, J., Postmes, T., \& Haslam, C. (2009). Social identity, health and well-being: An emerging agenda for applied psychology. Applied Psychology, 58, 1-23. Doi:10.1111/j.1464-0597.2008.00379.x 
Hayes, A. F., Preacher, K. J., \& Myers, T. A. (2011). Mediation and the estimation of indirect effects in political communication research. Sourcebook for Political Communication Research: Methods, Measures, and Analytical Techniques, 434-465.

Higgins, E. T., King, G. A., \& Mavin, G. H. (1982). Individual construct accessibility and subjective impressions and recall. Journal of Personality and Social Psychology, 43, 3547. Doi:10.1037/0022-3514.43.1.35

Hutter, R. R., Wood, C., \& Turner, R. N. (2013). Individuation moderates impressions of conflicting categories for slower processors. Social Psychology, 44, 239-247.

Doi:10.1027/1864-9335/a000108

Institute Of Medicine. (2003). Health Professions Education: A Bridge to Quality. Washington, DC: Author.

Ki-Moon, B. (2010). Global strategy for women's and children's health. New York: United Nations. Leyens, J. P., Paladino, M. P., Rodriguez, R. T., Vaes, J., Demoulin, S., Rodriguez, A. P., et al. (2000). The emotional side of prejudice: The role of secondary emotions. Personality and Social Psychology Review, 4, 186-197.

Leyens, J. P., Rodriguez-Perez, A., Rodriguez-Torres, R., Gaunt, R., Paladino, M. P., Vaes, J., \& Demoulin, S. (2001). Psychological essentialism and the differential attribution of uniquely human emotions to ingroups and outgroups. European Journal of Social Psychology, 31, 395-411. Doi:10.1002/ejsp.50

Louis, W. R., Duck, J. M., Terry, D. J., Schuller, R. A., \& Lalonde, R. N. (2007). Why do citizens want to keep refugees out? Threats, fairness and hostile norms in the treatment of asylum seekers. European Journal of Social Psychology, 37, 53-73. Doi:10.1002/ejsp.329

Major, B., Mendes, W. B., \& Dovidio, J. F. (2013). Intergroup relations and health disparities: a social psychological perspective. Health Psychology, 32, 514-524. Doi:10.1037/a0030358 
Matthews, K. A., \& Gallo, L. C. (2011). Psychological perspectives on pathways linking socioeconomic status and physical health. Annual Review of Psychology, 62, 501-530. Doi:10.1146/annurev.psych.031809.130711

Mikuls, T. R., Saag, K. G., George, V., Mudano, A. S., \& Banerjee, S. (2005). Racial disparities in the receipt of osteoporosis related healthcare among community-dwelling older women with arthritis and previous fracture. The Journal of Rheumatology, 32, 870-875.

Miller, K. P., Brewer, M. B., \& Arbuckle, N. L. (2009). Social identity complexity: Its correlates and antecedents. Group Processes \& Intergroup Relations, 12, 79-94.

Doi:10.1177/1368430208098778

Mudano, A. S., Casebeer, L., Patino, F., Allison, J. J., Weissman, N. W., Kiefe, C. I., ... \& Saag, K. G. (2003). Racial disparities in osteoporosis prevention in a managed care population. Southern Medical Journal, 96, 445-451. Doi:10.1097/01.SMJ.0000053918.93363.B0

Nascimbene, B., \& Di Pascale, A. (2011). The 'Arab spring' and the extraordinary influx of people who arrived in Italy from North Africa. European Journal of Migration and Law, 13, 341-360. Doi:10.1163/157181611X605855

Penner, L. A., Albrecht, T. L., Coleman, D. K., \& Norton, W. E. (2007). Interpersonal perspectives on Black-White health disparities: Social policy implications. Social Issues and Policy Review, 1, 63-98. Doi:10.1111/j.1751-2409.2007.00004.x

Pettaway, C. A. (1999). Racial differences in the androgen/androgen receptor pathway in prostate cancer. Journal of the National Medical Association, 91, 653-660.

Pettigrew, T. F., \& Meertens, R. W. (2001). In defense of the subtle prejudice concept: A retort. European Journal of Social Psychology, 31, 299-309. Doi:10.1002/ejsp.45

Pickett, C. L., \& Brewer, M. B. (2001). Assimilation and differentiation needs as motivational determinants of perceived in-group and out-group homogeneity. Journal of Experimental Social Psychology, 37, 341-348. Doi:10.1006/jesp.2000.1469 
Prati, F., Menegatti, M., \& Rubini, M. (2015). Reducing linguistic outgroup derogation: A matter of multiple categorization and intergroup contact. Journal of Language and Social Psychology. 34, 475-500. Doi: 10.1177/0261927X14567777

Prati, F., Moscatelli, S., Pratto, F., \& Rubini, M. (2015). Predicting Support for Arabs’ Autonomy from Social Dominance: the Role of Identity Complexity and Dehumanization. Political Psychology. Advance online publication. Doi: 10.1111/pops.12274

Prati, F., Vasiljevic, M., Crisp, J. R., \& Rubini, M. (2015). Some extended psychological benefits of challenging social stereotypes: Decreased dehumanization and a reduced reliance on heuristic thinking. Group Processes and Intergroup Relations. 18, 801-816.

Doi:10.1177/1368430214567762

Pratto, F., Çidam, A., Stewart, A.L., Bou Zeineddine, F., Aranda, M., Aiello, A., ... Henkel, K.E. (2013). Social dominance in context and in individuals: Contextual moderation of robust effects of social dominance orientation in 15 languages and 20 countries. Social Psychology and Personality Science, 4, 587-599. Doi: 10.1177/1948550612473663

Pratto, F., \& Glasford, D. E. (2008). Ethnocentrism and the value of a human life. Journal of Personality and Social Psychology, 95, 1411-1428. Doi:10.1037/a0012636

Pratto, F., Sidanius, J., Stallworth, L. M., \& Malle, B. F. (1994). Social dominance orientation: A personality variable predicting social and political attitudes. Journal of Personality and Social Psychology, 67, 741-763. Doi: 10.1037/0022-3514.67.4.741

Roccas, S., \& Brewer, M. B. (2002). Social identity complexity. Personality and Social Psychology Review, 6, 88-106. Doi:10.1207/S15327957PSPR0602_01

Rosenthal, H. E., \& Crisp, R. J. (2006). Reducing stereotype threat by blurring intergroup boundaries. Personality and Social Psychology Bulletin, 32, 501-511.

Doi:10.1177/0146167205281009 
Rosenthal, H. E., Crisp, R. J., \& Suen, M. W. (2007). Improving performance expectancies in stereotypic domains: Task relevance and the reduction of stereotype threat. European Journal of Social Psychology, 37, 586-597. Doi:10.1002/ejsp.379

Rubini, M., Moscatelli, S., \& Palmonari, A. (2007). Increasing Group Entitativity Linguistic Intergroup Discrimination in the Minimal Group Paradigm. Group processes \& intergroup relations, 10, 280-296. Doi: 10.1177/1368430207075156

Schmid, K., Hewstone, M., Tausch, N., Cairns, E., \& Hughes, J. (2009). Antecedents and consequences of social identity complexity: Intergroup contact, distinctiveness threat, and outgroup attitudes. Personality and Social Psychology Bulletin, 35, 1085-1098.

Doi:10.1177/0146167209337037

Schnittker, J., \& McLeod, J. D. (2005). The social psychology of health disparities. Annual Review of Sociology, 75-103. Doi:10.1146/annurev.soc.30.012703.110622

Sentell, T. L., \& Halpin, H. A. (2006). Importance of adult literacy in understanding health disparities. Journal of General Internal Medicine, 21, 862-866.

Smedley, B. D., Stith, A. Y., \& Nelson, A. R. (2003). Committee on understanding and eliminating racial and ethnic disparities in health care, board on health sciences policy, Institute of Medicine. Unequal Treatment: Confronting Racial and Ethnic Disparities in Health Care, 160-79.

Tajfel, H. (1978). Social categorization, social identity and social comparison. In H. Tajfel (Ed.), Differentiation between Social Groups: Studies in the Social Psychology of Intergroup Relations (pp. 61-76). London: Academic Press.

Tajfel, H., Billig, M. G., Bundy, R. P., \& Flament, C. (1971). Social categorization and intergroup behaviour. European Journal of Social Psychology, 1, 149-178.

Doi:10.1002/ejsp.2420010202 
Tajfel, H., \& Turner J. C. (1979). An Integrative theory of social conflicts. In W. G. Austin, \& S. Worchel (Eds.), The Social Psychology of Intergroup Relations (pp. 33-47). Monterey: Brooks-Cole.

UNCHR: The Right to Health. Factsheet 31 OHCHR-WHO (2008).

[http://www2.ohchr.org/english/issues/health/right/], accessed on 22/01/2011.

Vanbeselaere, N. (1987). The effect of dichotomous and crossed social categorizations upon intergroup discrimination. European Journal of Social Psychology, 17, 143-156.

Doi:10.1002/ejsp.2420170203

Vasiljevic, M., \& Crisp, R. J. (2013). Tolerance by surprise: Evidence for a generalized reduction in prejudice and increased egalitarianism through novel category combination. PLoS ONE 8: e57106. Doi:10.1371/journal.pone.0057106

Verkuyten, M., \& Martinovic, B. (2012). Immigrants' national identification: Meanings, determinants, and consequences. Social Issues and Policy Review, 6, 82-112. Doi:10.1111/j.1751-2409.2011.01036.x

Williams, D. R., \& Jackson, P. B. (2005). Social sources of racial disparities in health. Health Affairs, 24, 325-334. Doi:10.1377/hlthaff.24.2.325

Williams, D. R., \& Mohammed, S. A. (2009). Discrimination and racial disparities in health: evidence and needed research. Journal of Behavioral Medicine, 32, 20-47.

\section{Notes}

1 It should be noted that previous research in the multiple categorization domain employed multiple ingroup (i.e., social affiliations which participants and target have in common) and multiple outgroup (i.e., social affiliations which the target group does not share with participants and target) variants of this strategy (e.g. Crisp, Hewstone \& Rubin, 2001). Albarello and Rubini (2012) employed a single, mixed multiple categorization condition in which some social affiliations of the target were shared by participants and some were not shared (Albarello \& Rubini, 2012). To 
provide the fullest test of the effectiveness of the multiple categorization approach in our study we included all three different variants of multiple categorization intervention used in previous research.

2 Since in previous research SIC has been measured also in terms of perceived similarity among group memberships, respondents rated on 7-point scales $(1=$ strongly disagree, $7=$ strongly agree $)$ the extent to which they thought that "Being a member of your national (political/ professional) group means the same as being a member of your political (professional/ political) group?", “A typical member of your national (political/ professional) group is very similar to the typical member of your political (professional/ national) group?". Items were reversed, so that higher scores were indicative of greater similarity complexity $(\alpha=.88)$. The measure of similarity complexity did not correlate with the measure of overlap complexity $r=.17$.

${ }^{3}$ The mediating role of individualization in the relationship between categorization type and support for vaccination was tested at the two values of low and high SIC also using the measure of perceived similarity complexity. For participants who scored low in SIC, individualization mediated the effects of categorization type on support for vaccination $(B=0.60, S E=0.19 ; p=.003 ; \mathrm{CI}=$ LL: .20, UL .99). For participants who scored high in SIC, individualization mediated the effects of categorization type on support for vaccination $(B=-0.003, S E=0.18 ; p=.98 ; \mathrm{CI}=\mathrm{LL}:-.37, \mathrm{UL}$ 0.36).Thus, supporting findings of the main analyses, SIC moderated the indirect effect of multiple categorization on support for vaccination through individualization. 
Table 1. Means (standard deviations) and inter-correlations of individuation of immigrants, financial support for immigrants' vaccination to health and social identity complexity.

\begin{tabular}{lcccc}
\hline & $M(S D)$ & 1. & 2. & 3. \\
\hline 1. Individuation of immigrants & $4.04(1.49)$ & -- & $.25^{* *}$ & $.26^{* *}$ \\
$\begin{array}{l}\text { 2. Financial support for immigrants } \\
\text { vaccination }\end{array}$ & $4.84(1.73)$ & & -- & .04 \\
3. Social identity complexity & $53.05(21.28)$ & & & -- \\
\hline
\end{tabular}

Note. $* p<.05 ; * * p<.01$ 
Figure 1. Support for vaccination as a function of social identity complexity and categorization.

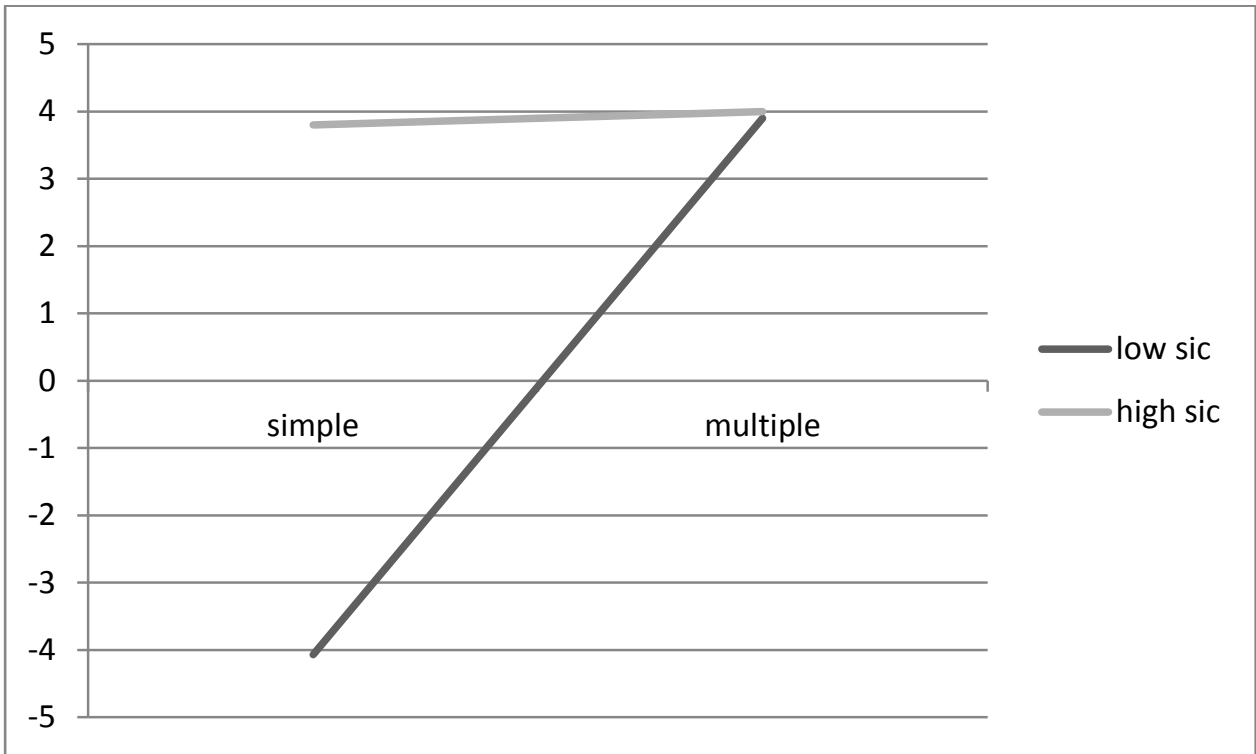

